\title{
İki Bileşenli Weibull Dağılımı ile Rüzgâr Hızı Olasılık Dağılımlarının Modellenmesi
}

\author{
Kadir Doğanşahin ${ }^{1 *}$, Ahmet Furkan Uslu, Bedri Kekezoğlu ${ }^{3}$ \\ ${ }^{1}$ Artvin Çoruh Üniversitesi, Mühendislik Fakültesi, Elektrik Elektronik Mühendisliği Bölümü, Artvin, Türkiye (ORCID: 0000-0002-6763-058X) \\ ${ }^{2}$ Yıldız Teknik Üniversitesi, Elektrik Elektronik Fakültesi, Elektrik Mühendisliği Bölümü, İstanbul, Türkiye (ORCID: 0000-0002-1202-913X)
}

(İlk Geliş Tarihi 4 Ocak 2019 ve Kabul Tarihi 5 Mart 2019)

(DOI: 10.31590/ejosat.505723)

ATIF/REFERENCE: Doğanşahin, K., Uslu, A. F. \& Kekezoğlu, B. (2019). İki Bileşenli Weibull Dağılımı ile Rüzgâr Hızı Olasılık Dağılımlarının Modellenmesi. Avrupa Bilim ve Teknoloji Dergisi, (15), 315-326.

$\ddot{O} \mathbf{z}$

Rüzgar enerjisi elektrik enerjisi üretiminde tercih edilen en önemli yenilenebilir enerji kaynaklarından biridir. Sürdürülebilir, ekonomik ve çevre dostu bir enerji kaynağı olması yönüyle öne çıkmaktadır. Ekonomik ve çevresel endişelerin her geçen gün daha fazla hissedilmekte olduğu bir ortamda, rüzgar gibi bir enerji kaynağından olabildiğince fazla bir şekilde faydalanmak oldukça büyük önem arz etmektedir. Nitekim izlenen politikalar ve sektördeki eğilim bu yönde seyretmektedir. Diğer taraftan rüzgar hızının değişken olması, kontrol edilememesi ve başka yere aktarılamaması gibi nedenlerden dolayı rüzgar enerjisi ile elektrik üretiminde çeşitli belirsizlikler ve bu belirsizliklere bağlı bazı sorunlar yaşanabilmektedir. Söz konusu belirsizlikleri en aza indirgemek ve yaşanabilecek sorunları önleyebilmek amacıyla rassal bir değişken olan rüzgar hızının olasılık dağılımları ile istatistiksel modellemesi üzerine çeşitli çalışmalar gerçekleştirilmiştir. Literatürde yapılan çalışmaların geneli ve uluslararası standartlardan bazıları, rüzgar hızının istatistiksel analizlerinde iki değiş̧kenli basit Weibull dağılımının uygunluğu noktasında birleşmektedir. Bu çalışmada faaliyette olan bir rüzgar enerji santrali üzerinden alınan rüzgar hızı ve çıkış gücü verileri analiz edilmiştir. İlk olarak literatürde yaygın olarak önerilen iki değişkenli Weibul dağılımı kullanılarak mevcut verinin istatiksel modellemesi incelenmiştir. Uygun Weibull dağılımının elde edilebilmesi amacıyla olasılık yoğunluk fonksiyonu değişkenleri, farklı matematiksel yöntemler kullanılarak hesaplanmıştır. Her bir yöntem ile elde edilen Weibull dağılımları çeşitli istatistiksel hata analizleri üzerinden değerlendirilerek, en yüksek doğruluğa sahip dağılım ve dolayısıyla değişken hesaplamaları açısından en elverişli matematiksel yöntemin tespiti yapılmaya çalışılmışır. Çalışmanın son bölümünde rüzgar hızı verilerinin, karma Weibull dağılımına uygunluğu irdelenmiştir. Bu amaçla iki bileşenli karma Weibul olasılık yoğunluk fonksiyonu için en başarılı matematiksel yöntem olarak öne çıan en çok olabilirlik yöntemi kullanılarak değişkenler hesaplanmıştır. Tanımlanan karma Weibul dağılımı, basit Weibull dağılımları için gerçekleştirilen hata analizlerinin tamamına tabi tutulmuştur. Elde edilen hata metrikleri, karma Weibull dağılımının, iki değişkenli basit Weibull dağılımlarına oranla daha yüksek doğrulukta olduğu kanıtlamıştır. Son olarak, çalışmada değerlendirilen tüm olasılık dağılımları üzerinden rüzgar enerjisi ile üretilebilecek elektrik enerjisi potansiyeli hesaplanmış ve santralden alınan gerçek veriler ile karşılaştırılmıştır. Ulaşılan sonuçlar, karma Weibull dağılımının enerji potansiyeli hesaplamalarında da alternatiflerine göre daha yüksek başarı gösterdiğini ortaya koymuştur.

Anahtar Kelimeler: Rüzgar, Weibull, Kapasite Faktörü, Karma Dağılımlar.

\footnotetext{
${ }^{*}$ Sorumlu Yazar: Artvin Çoruh Üniversitesi, Mühendislik Fakültesi, Elektrik Elektronik Mühendisliği Bölümü, Artvin, Türkiye, ORCID: 0000-00026763-058X, dogansahin@artvin.edu.tr
} 


\title{
Modeling of Wind Speed Probability Distribution with Two- Component Weibull Distributions
}

\begin{abstract}
Wind energy is one of the most important renewable energy sources preferred in electricity energy generation. Sustainable, economical and environmentally friendly features distinguish wind energy from traditional energy sources. In an atmosphere where economic and environmental concerns rise increasingly, it is of great importance to utilize from an energy source such as wind energy as much as possible. As a matter of fact, the policies followed and the tendency in the sector are in this direction. Due to the reasons such as intermittency andy uncontrollability of wind speed, and the inability of wind energy to be transferred to another point, various uncertainties and some problems in relation to that uncertainties may arise in electricity generation from wind energy. Bu belirsizlikleri en aza indirmek ve oluşabilecek sorunları önlemek için, rastgele bir değişken olan rüzgar hızının olasılık dağılımı ve istatistiksel modellenmesi üzerine sayısız araştırma yapılmıştır. Most of of the studies conducted in the literature and some of the international standards imply on the suitability of the two -variable basic Weibull distribution use at statistical analysis of wind speed. In this study, wind speed and power outpu data taken from a wind power plant in operation is analyzed. Firstly, statistical modeling of the available data has been investigated by using the two-variable basic Weibul distribution. In order to obtain the appropriate Weibull distribution, probability density function variables have been calculated by using different mathematical methods. Weibull distributions obtained by each methods are evaluated through various statistical error analysis. By this way, the distirbution in the highest accurcy and hence the optimal mathematical method for the variable calculations are obtained. In the last part of the study, the suitability of wind speed data to the mixed Weibull distribution was examined. For this purpose, the variables of the two-component mixed Weibull probability density function were calculated using the maximum likelihood method, which is determined as the most successful mathematical method. The defined mixed Weibul distribution has been subjected to all of the error analyzes performed for basic Weibull distributions. The resulting error metrics proved that the mixed Weibull distribution is more accurate than the basic Weibull two-variable distributions. Finally, the electrical energy expected to be generated by wind energy is calculated and compared with the actual data obtained from the power plant. The results showed that the two-component mixture Weibull distribution is more successful in the calculation of the energy potential than the alternatives.
\end{abstract}

Keywords: Wind energy, Weibull, Capacity Factor, Karma Dağılımlar. .

\section{Giriş}

Dünya nüfusundaki artış, gelişmekte olan teknoloji ve yükselen yaşam standartları enerjiye olan ihtiyacı artırmaktadır. Artan enerji ihtiyacı içerisinde, nihai bir enerji çeşidi olan elektrik enerjisi, büyük bir öneme sahiptir. Nitekim gerçekleştirilen tahmin çalışmalarına göre, önümüzdeki 25 yıl içerisinde beklenen küresel enerji ihtiyacındaki artışın \%70’i oranındaki kısmı elektrik enerjisi ihtiyacındaki artışlar tarafından oluşturulacağı öngörülmektedir [1]. Dolayısıyla ilerleyen zaman içerisinde enerji sektöründe gerçekleştirilecek yatırımların elektrik enerjisi üzerine yoğunlaşması beklenmektedir. Bunun yanı sıra, her geçen gün, ekonomik ve çevresel duyarlılıklar artış göstermekte ve enerji arzında sürdürülebilirlik, güvenlik, güvenilirlik ve verimlilik gibi konuların önem kazanmaktadır. Bu süreç içerisinde, düşük maliyetli, sürdürülebilir ve çevre dostu olan yenilenebilir enerji kaynakları ön plana çıkmış ve günümüzde elektrik enerjisi üretiminde oldukça fazla bir şekilde rağbet görmektir [2].

Rüzgar enerjisi, elektrik enerjisi üretiminde kullanılan yenilenebilir enerji kaynaklarından birisi olarak günümüzde önemli bir yere sahiptir. Ülkemiz açısından değerlendirildiğinde, Elektrik İşleri Etüt İdaresi (EİEİ) ve Meteoroloji Genel Müdürlüğü (MGM) tarafından gerçekleştirilen "Türkiye Rüzgar Enerjisi Potansiyel Atlası" (REPA) çalışması neticesinde, ülkemizin rüzgar enerjisi potansiyelinin yaklaşık $66 \mathrm{GW}$ olduğu tespit edilmiştir [3]. Bu potansiyelin değerlendirilmesi, elektrik enerjisi üretiminde ağırlıklı olarak fosil tabanlı yakıtlara bağımlı olan ülkemizin, enerji kaynaklarında dışa bağımlılığının azaltılması, enerji güvenilirliğinin ve çeşitliliğinin artırılması yönünden oldukça önemlidir.

Diğer taraftan, rüzgârın kararsız değişkenlikte kontrol edilemez yapısı, elektrik enerjisi üretiminde bir enerji kaynağı olarak kullanımı noktasında çeşitli olumsuzluklara yol açabilmektedir. Bunun yanı sıra, mevcut teknolojiler göz önünde bulundurulduğunda, her hızdaki rüzgâr ile elektrik enerjisi üretimi gerçekleştirebilmek hem teknik hem de ekonomik açıdan pek mümkün değildir. Dolayısıyla, yatırımların gerçekleştirilebilirlik analizlerinde rüzgar hızı ile alakalı çeşitli öngörülere ihtiyaç duyulmaktadır. Bu öngörülerin üretilebilmesi amacıyla rüzgar hızının istatistiksel analizi üzerine literatürde birçok çalışma gerçekleştirilmiştir [4].

Gerçekleştirilen çalışmaların geneli, bir konumda belirli bir zaman aralığına ait rüzgar hızlarının olasılık dağılımlarının belirlenmesine yöneliktir [5,6]. Literatürdeki çalışmalar incelendiğinde, rüzgar hızları için en uygun olasılık dağılımı olarak Weibull olasılık dağılımın öne çıktığı görülmektedir. Weibull olasılık dağılımını ifade eden değişkenlerin, eldeki mevcut verilere göre belirlenebilmesi amacıyla çeşitli matematiksel yöntemler kullanılabilmektedir [7,8]. Bu matematiksel yöntemler kullanılarak belirlenen değişkenler üzerinden tanımlı olasılık dağılım fonksiyonlarının eldeki verilere uygunluğu üzerinden matematiksel modellerin doğruluğu değerlendirilmiştir. Yapılan çalışmalarda sıklıkla başvurulan çeşidi ve en temel tanımı ile iki değişkenli Weibull olasılık dağılımı şekil 
ve ölçek değişkeni olmak üzere iki farklı değişken üzerinden ifade edilebilmektedir ve tek tepeli bir olasılık dağılımıdır. Bunun yanı sıra, daha fazla değişken ile ifade edilebilen çeşitli Weibull olasılık dağılımları da mevcuttur.

Rüzgar Enerjisi Santralleri (RES) kurulumuna yönelik yatırımların gerçekleştirilebilirlik analizlerinde, santralin kurulacağı konuma ait yıllık rüzgar verileri üzerinden teknik ve ekonomik incelemeler gerçekleştirilir [9]. Yapılan bu incelemeler sonucunda elde edilen değerlerin doğruluğu oldukça önemlidir. Yılın dönemlerine göre hakim olan rüzgar hızları farklılık gösterebilmektedir. Dolayısıyla, bir yıllık rüzgar hızı verisinde, verilerin birden farklı rüzgar hızı çevresinde yoğunlaşması mümkündür. Böylesi durumlarda, rüzgar hızı verisinin tek tepeli olasılık dağılımları üzerinden ifade yeterli uyumluluk sağlayamamaktadır. Haliyle, olasılık dağılımı kullanılarak gerçekleştirilecek analizlerde elde edilen sonuçlar, olasılık dağılımının veriye uyumsuzluğu mertebesinde hatalı olacaktır. Bu noktada, karma olasılık dağılımları öne çıkmaktadır. Çeşitli olasılık dağılımlarının farklı oranlarda katılımları ile oluşturulan karma olasılık dağılımları, çok tepeli verilerin olasılık dağılımlarını ifade etmeye daha elverişlidir [10].

Bu çalışmada, faaliyetteki bir RES’ten, rüzgar hızı ve enerji çıkışına ait bir yıllık ölçümler üzerinden çalışma gerçekleştirilmiştir. Çalışmanın ilk aşamasında, sahadan alınan rüzgar verisi, iki değişkenli Weibull dağılımı üzerinden ifade edilmiştir. Olasıllk dağılım fonksiyonu değişkenlerinin hesaplanmasında, literatürde sıklıkla başvurulan matematiksel yöntemlerden faydalanılmıştır. Elde edilen değişkenler ile oluşturulan Weibull olasılık yoğunluk fonksiyonlarının, rüzgar verisine olan uygunluklarını incelemek amacıyla farklı istatistiksel hata analiz yöntemleri kullanılarak değerlendirmeler yapılımıştır. Aynı işlemler, karma Weibull olasıllık dağılımı için tekrarlanmış ve sonuçlar karşılaştırılmıştır. Çalışmanın son kısmında, sahadan alınan enerji çıkışı ölçümleri üzerinden kapasite faktörü hesaplanmış ve çalışmada elde edilen tüm Weibull dağılımları için hesaplanan kapasite faktörleri ile karşılaştırılmıştır. Yapilan tüm değerlendirmelerin neticesinde, Weibull dağılımlarının rüzgar enerjisi potansiyeli çalışmaları açısından performansları yorumlanmıştır.

\section{Materyal ve Metot}

\subsection{Rüzgâr Hızı Verisinin İncelenmesi}

Rüzgar enerjisi potansiyeli değerlendirmelerinde en önemli faktör, atmosferik olaylar içerisinde oldukça değişken ve öngörülmesi en zor olan rüzgar hızıdır [11]. Ölçümlerin alındığı sahada yer alan rüzgar türbini yatay eksenli yapıya sahiptir. Yatay eksenli türbinlerde, rüzgar türbini, değişen rüzgar yönlerine uyum sağlayacak şekilde dönme hareketi yapabilmektedir. Ancak rüzgar yönü değişimleri, enerji dönüşümünde çeşitli kayıplara yol açabilmektedir [12]. Bu kayıplar, yapılacak değerlendirmeler açısından çok büyük etkiye sahip değildir. Rüzgar yönü ile alakalı Şekil - 1'de verilen görselden de anlaşılacağı üzere ölçümlerin alındığı saha için hakim bir rüzgar yönü bulunmaktadır. $\mathrm{Bu}$ nedenle çalışma içerisinde gerçekleştirilecek değerlendirmeler rüzgar yönü değişikliğinden fazlaca etkilenmeyecektir.

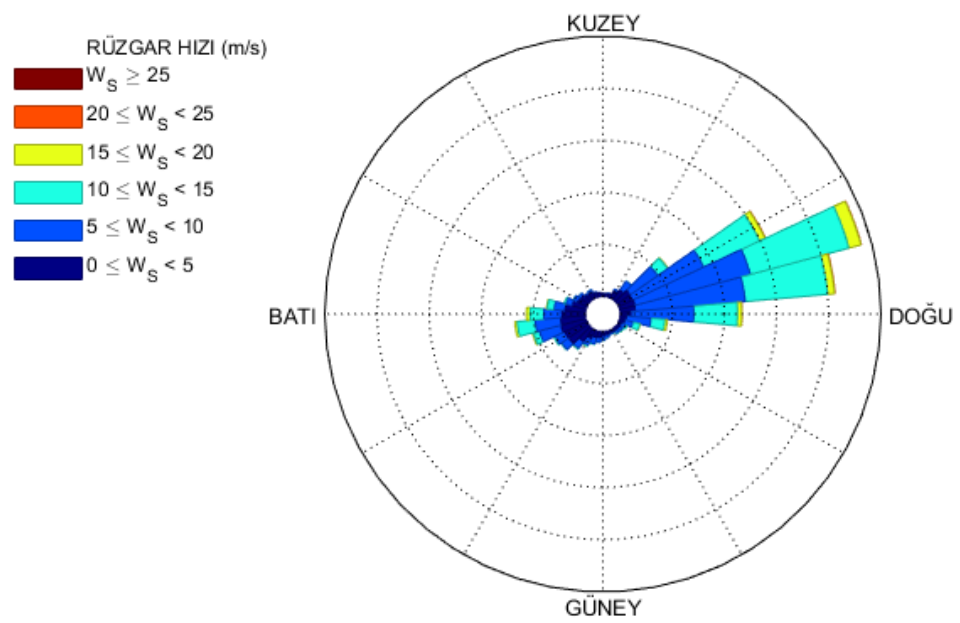

Şekil 1 Ölçümlerin alındığı sahada rüzgar hızları ve yönleri

Rüzgar enerjisi santrali yatırımları için mevcut düzenlemeler gereği en az bir yıllık veriye ihtiyaç duyulmaktadır. Gerçekleştirilen çalışmada kullanılan rüzgar hızı verisi, bir yıla ait $10^{\prime}$ ar dakikalık ortalamalardan oluşmaktadır. Ölçümler sonucu elde edilen rüzgar hızının aylar içerisinde günlere göre değişimi Şekil - 2 ile gösterilmiştir. 

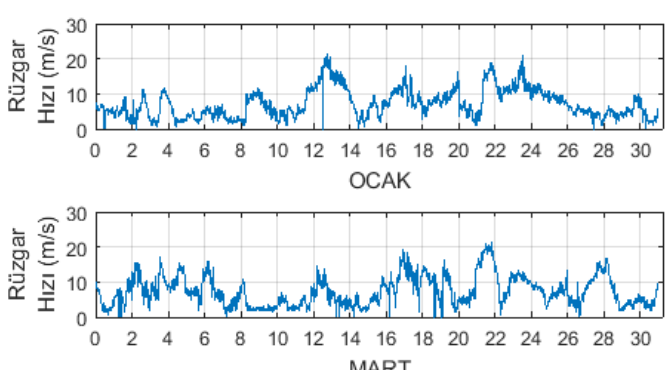
MART
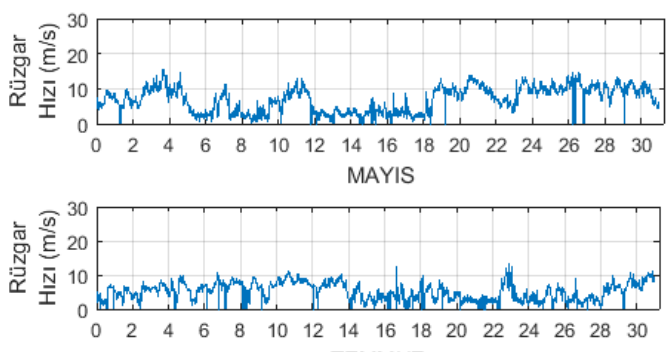
TEMMUZ
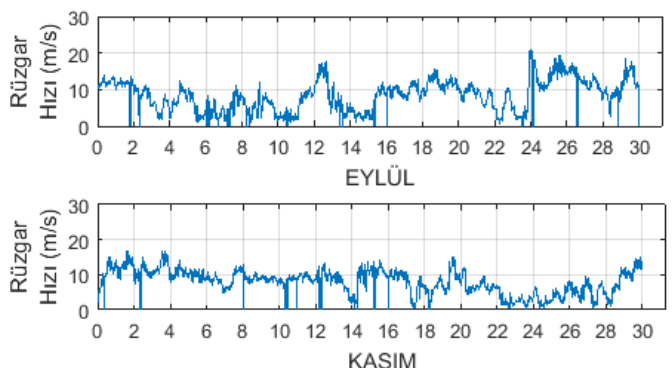
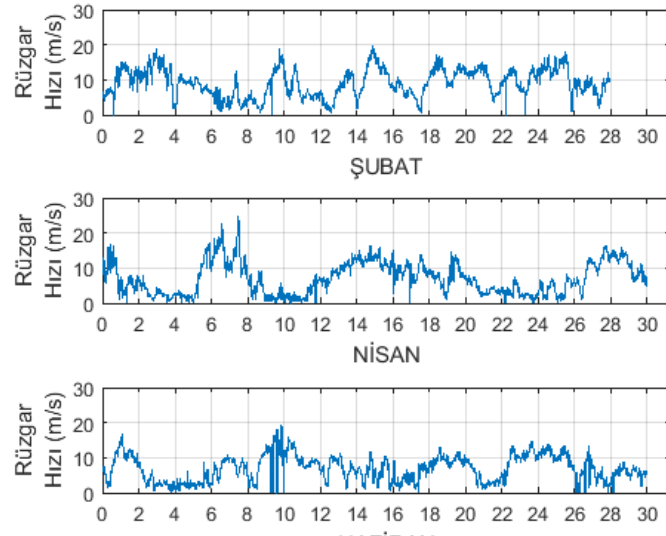
HAZIRAN
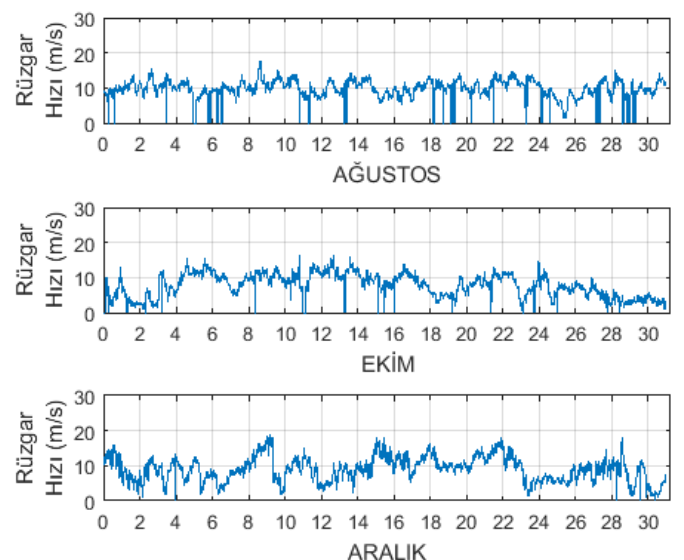

Şekil 2 Mevcut veriye göre rüzgar hızının aylar içerisindeki değişimi
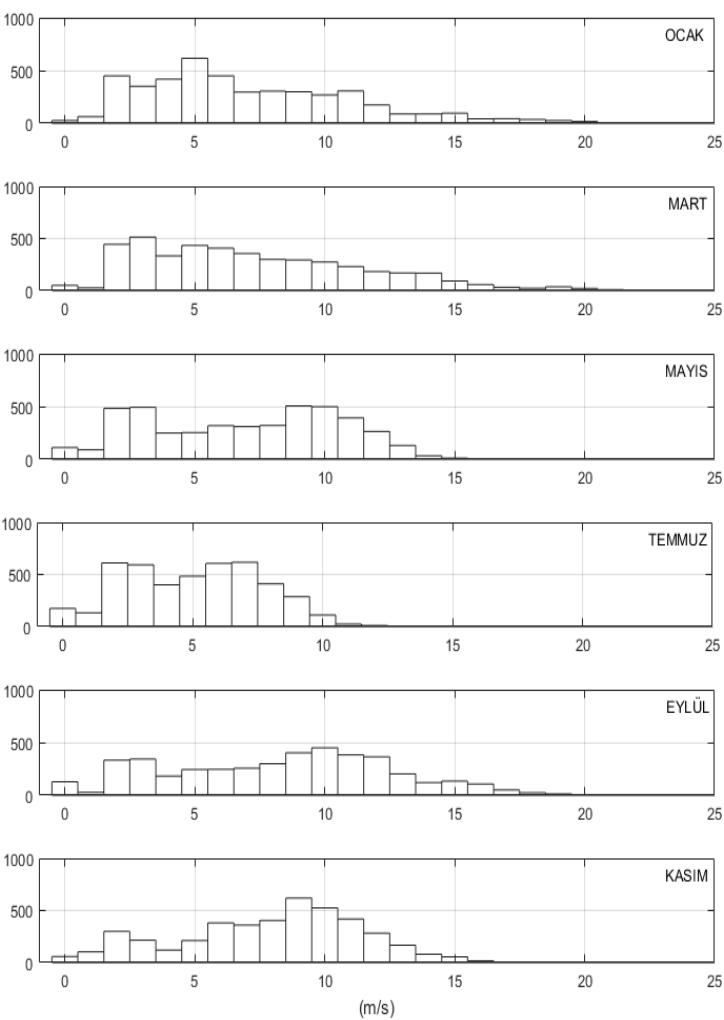
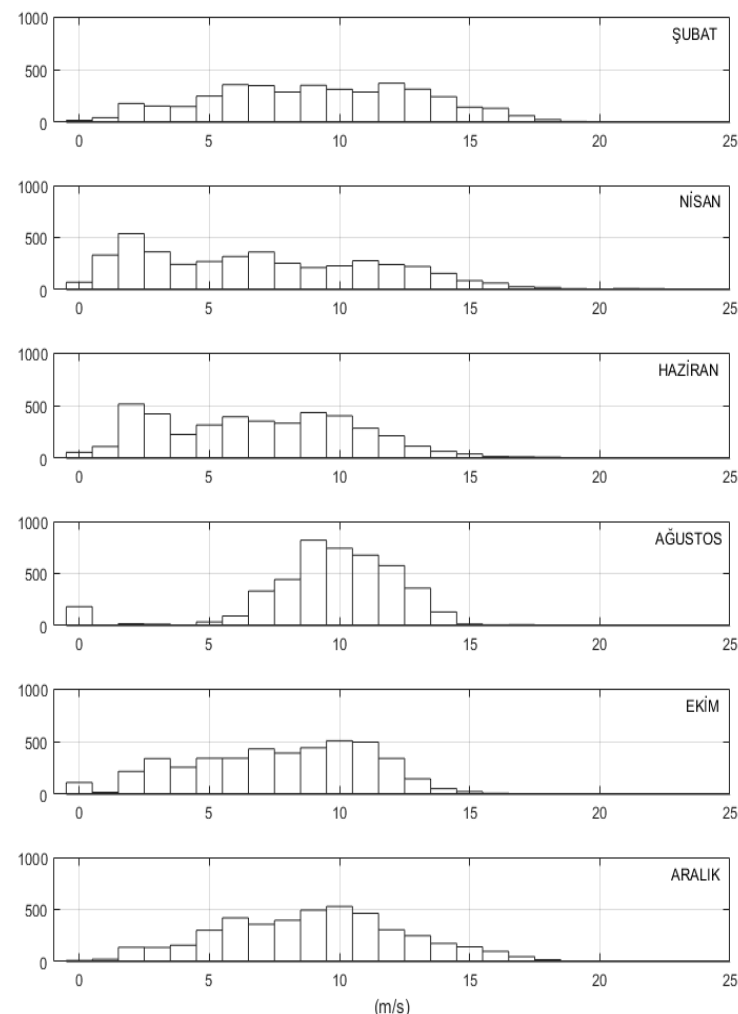

Şekil 3 Rüzgar hızlarının aylar içerisindeki histogramı

Mevcut rüzgar verisine göre Ağustos ve Şubat ayları en yüksek rüzgar hızı ortalamasına sahip iken, Temmuz ve Haziran ayları en düşük rüzgar hızı ortalamasına sahip aylardır. Şekil 3’te ise aylar içerisinde ölçülen belirli aralıklardaki rüzgâr hızlarının histogramı verilmiştir. Görüldüğü üzere her ay için en çok sıklıkla gerçekleşen rüzgar hızları birbirlerinden farklıdır. Bir aya ait rüzgar hızı 
histogramı ile söz konusu aya ait rüzgar hızı olasıllk dağılımları birbirlerine paralellik gösterir. Bu durum göz önünde bulundurulduğunda, bazı aylar için rüzgar hızı olasılık dağılımının ifadesinde Weibull dağılımının yetersiz kalabileceği anlaşılmaktadır.

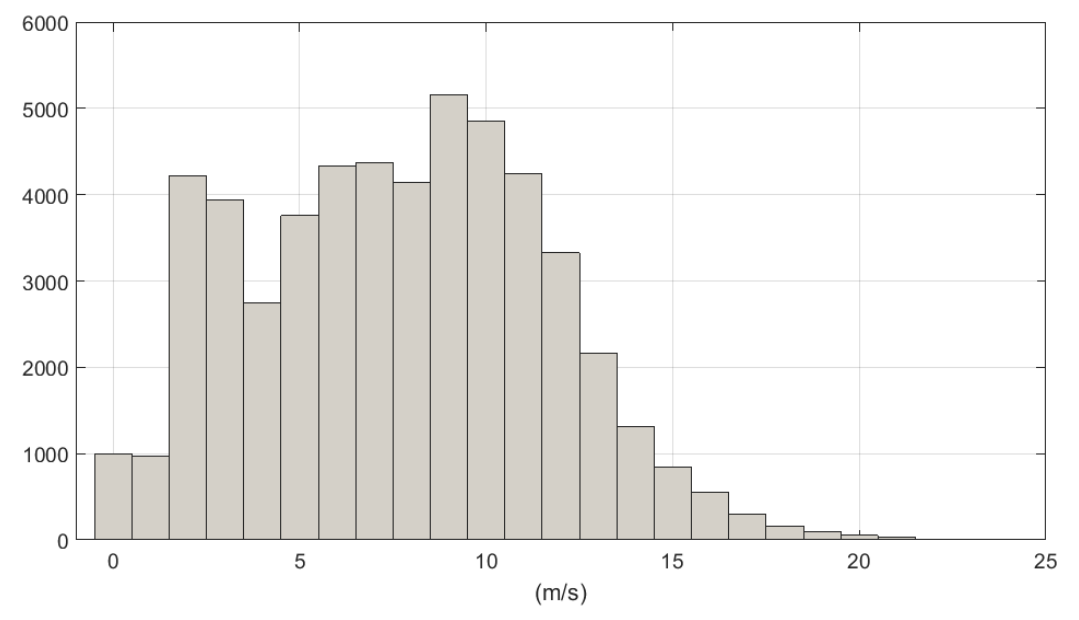

Şekil 4 Yıl boyunca ölçümlenen rüzgar hızlarının histogramı

Verilerin alındığı yıl boyunca ölçümlenen rüzgâr hızlarının histogramı Şekil - 4 ile verilmiştir. Şekilden görüldüğü üzere $9 \mathrm{~m} / \mathrm{s}$ ve $3 \mathrm{~m} / \mathrm{s}$ değerindeki rüzgar hızlarının olasılık yoğunlukları diğerlerine göre belirgin bir şekilde fazladır.

\subsection{Weibul Olasılık Dağılımı}

Weibull dağılımı, farklı özelliklerdeki önemli dağılımları içeren bir dağılım ailesini ifade etmektedir. Oldukça esnek ve sürekli bir yapıya sahip olan Weibull dağılımı, literatürde kabul edilmiş olasılık yoğunluk fonksiyonu tanımı ile Eşitlik (1)'de verildiği gibidir. Görüldüğü üzere, şekil (k) ve ölçek (c) değişkenleri olmak üzere iki farklı değişken üzerinden tanımlıdır.

$$
f(v ; k, c)=\frac{k}{c}\left(\frac{v}{c}\right)^{k-1} e^{-\left(\frac{v}{c}\right)^{k}}
$$

İncelenen verilerin değişimine göre olasılık dağılımının davranışını ifade eden şekil değiş̧keni (k), eğim değişkeni olarak da anılmaktadır. Şekil değişkeninin alabileceği bazı değerler ile literatürde tanımlı özel dağılımlar elde edilebilmektedir. Örneğin şekil değişkeninin 2 değerine eşit olması $(\mathrm{k}=2)$ ile Rayleigh dağılımı; 1 değerini alması neticesinde $(\mathrm{k}=1)$ üstel dağılım elde edilmektedir. Ölçek değiş̧keni (c) ise olasılık dağılımının yatay eksendeki genişliğinin ifadesidir. Literatürde kabul görmüş hali ile Weibull dağılımı tek tepeli bir yapıya sahiptir. Ölçek değişkeni arttıkça, Weibull dağılımının tepe yüksekliği azalacak ve dağılım sağa doğru genişleyecektir [13]. Uluslararası standartlarda ve çeşitli uygulama tavsiyelerine göre, rüzgar hızı verileri için en uygun olasıllk dağılımı iki değişkenli Weibull dağılımıdır [14].

Weibull değişkenlerinin elde edilmesine yönelik çeşitli matematiksel yöntemler kullanılmaktadır. Bu yöntemlerin, işlem performanslarını ve tutarlılıklarını incelemek amacıyla birçok çalışma gerçekleştirilmiştir [7,8]. Bu çalışmalarda, en yaygın olarak dikkate alınan matematiksel yöntemler kullanılarak, rüzgar hızı verilerine ait olasılık dağılımı için söz konusu değişkenler hesaplanmıştır. Yapılan çalışmada, farklı yöntemler ile değişkenleri hesaplanan Weibull dağılımlarına ek olarak, yine rüzgar hızı verilerine uygunluk gösteren ve literatürdeki çalışmalarda Weibull olasılık dağılımından sonra en fazla kullanılan Rayleigh dağılımının gerekli incelemeleri gerçekleştirilmiştir.

\subsection{Değişken Hesabında Kullanılan Matematiksel Yöntemler}

Literatürde, Weibull değişkenlerinin hesaplanması amacıyla sıklıkla kullanılan dört farklı matematiksel yöntemin kullanımına ve uygulanmasına ilişkin detaylara aşağıdaki başlıklarda değinilmiştir.

\subsubsection{Moment Yöntemi}

Mevcut veriye uygun Weibull dağılımının elde edilebilmesi amacıyla verinin çeşitli kademelerden momentleri ve olasılık yoğunluk fonksiyonu ifadesi üzerinden kurulan eşitlikler ile elde edilen denklem sisteminin çözümüdür. Bir veriye ait moment ifadesi Eşitlik (2) ile aşağıda verilmiştir.

$$
M_{r}=\frac{1}{n} \sum_{i=1}^{n} x_{i}^{r}
$$

burada, $M_{-} r$ verinin $r$ 'ninci dereceden momentini ifade etmektedir. $x_{-} i$, $i$ 'ninci veriye, $n$ ise veri sayısına karşılık gelmektedir. Olasılık yoğunluk fonksiyonu üzerinden moment ifadesi ise Eşitlik (3)'teki gibidir.

$$
M_{r}=c^{r} \Gamma\left(1+\frac{r}{k}\right)
$$


İki değişkenli Weibull dağılımı için birinci ve ikinci dereceden momentlerin ifadesi üzerinden oluşturulan eşitlikler, gerekli değişkenlerin bulunabilmesi için yeterli olacaktır.

\subsubsection{Grafik Yöntemi}

Grafik yöntemi, Weibull dağılım fonksiyonu üzerinden çeşitli işlem adımları sonrasında doğrusal bir denklemin elde edilmesi temeline dayan bir yöntemdir. Elde edilen doğrusal denklemin çözdürülmesi ile Weibull değişkenleri elde edilebilir [15]. Weibull kümülatif dağılım fonksiyonu Eşitlik (4) ile verilmiştir. Grafik yöntemi ile değişken hesaplama için takip edilen işlem adımları aşağıdaki gibidir.

$$
\begin{aligned}
& F(v)=1-e^{-\left(\frac{v}{c}\right)^{k}} \\
& 1-F(v)=e^{-\left(\frac{v}{c}\right)^{k}} \\
& \ln (1-F(v))=-\left(\frac{v}{c}\right)^{k} \\
& \ln (-\ln (1-F(v)))=k \cdot \ln \left(\frac{v}{c}\right) \\
& \ln (-\ln (1-F(v)))=k \ln (v)-k \ln (c)
\end{aligned}
$$

Eşitlik (8)'in sağ tarafinda elde edilen ifade, $\ln (v)$ 'ye göre doğrusal bir değişim göstermektedir. Elde edilen doğrusal denklem çözdürüldüğünde $\mathrm{k}$ ve $\mathrm{c}$ değişkenleri elde edilir.

\subsubsection{En Çok Olabilirlik Yöntemi}

Olabilirlik fonksiyonun tanımı her bir sıfırdan farklı veri için olasılık yoğunluk fonksiyonundan elde edilen değerlerin çarpımlarına karşılık gelmektedir. Bu açıdan değerlendirildiğinde Weibull dağılımı ile ifade edilen bir verinin olabilirlik fonksiyonu Eşitlik (9)'da verildiği gibidir.

$$
\begin{aligned}
& \mathcal{L}=\prod_{i=1}^{n} f\left(v_{i}\right) \\
& \mathcal{L}=\prod_{i=1}^{n} k c^{-k} v_{i}^{k-1} e^{-\left(\frac{v_{i}}{c}\right)^{k}}
\end{aligned}
$$

Eşitlik (10) ile verilen ifade üzerinden daha basit bir eşitlik elde edebilmek amacıyla logaritmik olabilirlik ifadesine geçiş yapılır ve elde edilen ifadenin maksimum noktası aranır.

$$
\begin{aligned}
& \log \mathcal{L}=\sum_{i=1}^{n} \ln (k)-k \ln (c)+(k-1) \ln \left(v_{i}\right)-\left(\frac{v_{i}}{c}\right)^{k} \\
& \log \mathcal{L}=\ln (k)-k \ln (c)+(k-1) \sum_{i=1}^{n} \ln \left(v_{i}\right)-c^{-k} \sum_{i=1}^{n} v_{i}^{k}
\end{aligned}
$$

Eşitlik (11)'deki ifadenin $\mathrm{k}$ ve c değişkenine göre türevleri alınarak sıfıra eşitlenir. Elde edilen eşitlikler iteratif yöntemler yardımıyla çözdürüldüğünde $\mathrm{k}$ ve $\mathrm{c}$ değişkenleri elde edilir.

\subsubsection{En Küçük Kareler Yöntemi}

En küçük kareler yöntemi, büyük hacimde verilerin analizinde sıklıkla kullanılmaktadır. Bu çalışmada, mevcut veri üzerinden, her bir veriye karşılık gelen gerçek kümülatif dağılımlar ile Weibull kümülatif dağılımları arasındaki farkın kareleri toplamını minimum değerine indirgemek yolu ile uygulanmıştır. Eşitlik (14), var olan hali ile doğrusal olmayan kısıtlamalı bir minimum değer problemi halini almıştır.

$$
\begin{aligned}
& \min \sum_{i=1}^{n}\left\{P_{i}-F\left(v_{i}\right)\right\}^{2} \\
& \min \sum_{i=1}^{n}\left\{P_{i}-\left(1-e^{-\left(\frac{v}{c}\right)^{k}}\right)\right\}^{2}
\end{aligned}
$$


Yukarıda verilen matematiksel yöntemlerin mevcut veriye uygulanması neticesinde elde edilen Weibull değişkenleri, Tablo - 1 ile listelenmiştir. Tablonun en son satırında, bir Weibull dağılımı türü olan Rayleigh fonksiyonu için hesaplanan şekil ve ölçek değişkenleri verilmiştir. Rayleigh dağılımının ölçek değişkeninin hesaplanmasında moment yöntemine başvurulmuştur.

Hesaplanan her bir şekil ve ölçek değişkeni ile olasılık yoğunluk fonksiyonları çizdirilmiştir. Şekil - 5 ile verilen olasılık yoğunluk fonksiyonları çizimlerinin arka planında, mevcut verideki rüzgar hızlarının histogramı çizdirilmiş. Rüzgar hızı verisine ait histogram ile elde edilen olasılık yoğunluk fonksiyonlarının biçimsel olarak birbirlerine benzer olması beklenir. Ancak şekilde de görüleceği üzere, bazı rüzgar hızlarına karşılık gelen olasılık yoğunlukları, olasılık yoğunluk fonksiyonlarınca eksik veya fazla hesaplanmaktadır. Farklı yöntemler üzerinden elde edilen weibull olasılık yoğunluk fonksiyonlarının veriye uygunluklarını incelemek amacıyla, çeşitli istatistiksel hata analiz yöntemleri kullanılabilir.

Tablo 1 Farklı matematiksel yöntemler kullanılarak elde edilen şekil ve ölçek değişkenleri

\begin{tabular}{|c|c|c|c|}
\hline & & $\mathbf{k}$ & c \\
\hline \multirow{5}{*}{ 言 } & Moment Yöntemi & 2.0381 & 8.6307 \\
\hline & Grafik Yöntemi & 2.0241 & 8.8195 \\
\hline & En fazla Olabilirlik Yöntemi & 2.1427 & 8.7853 \\
\hline & En küçük Kareler Yöntemi & 1.9662 & 8.9666 \\
\hline & Rayleigh olasılık dağılımı & 2 & 8.5972 \\
\hline
\end{tabular}

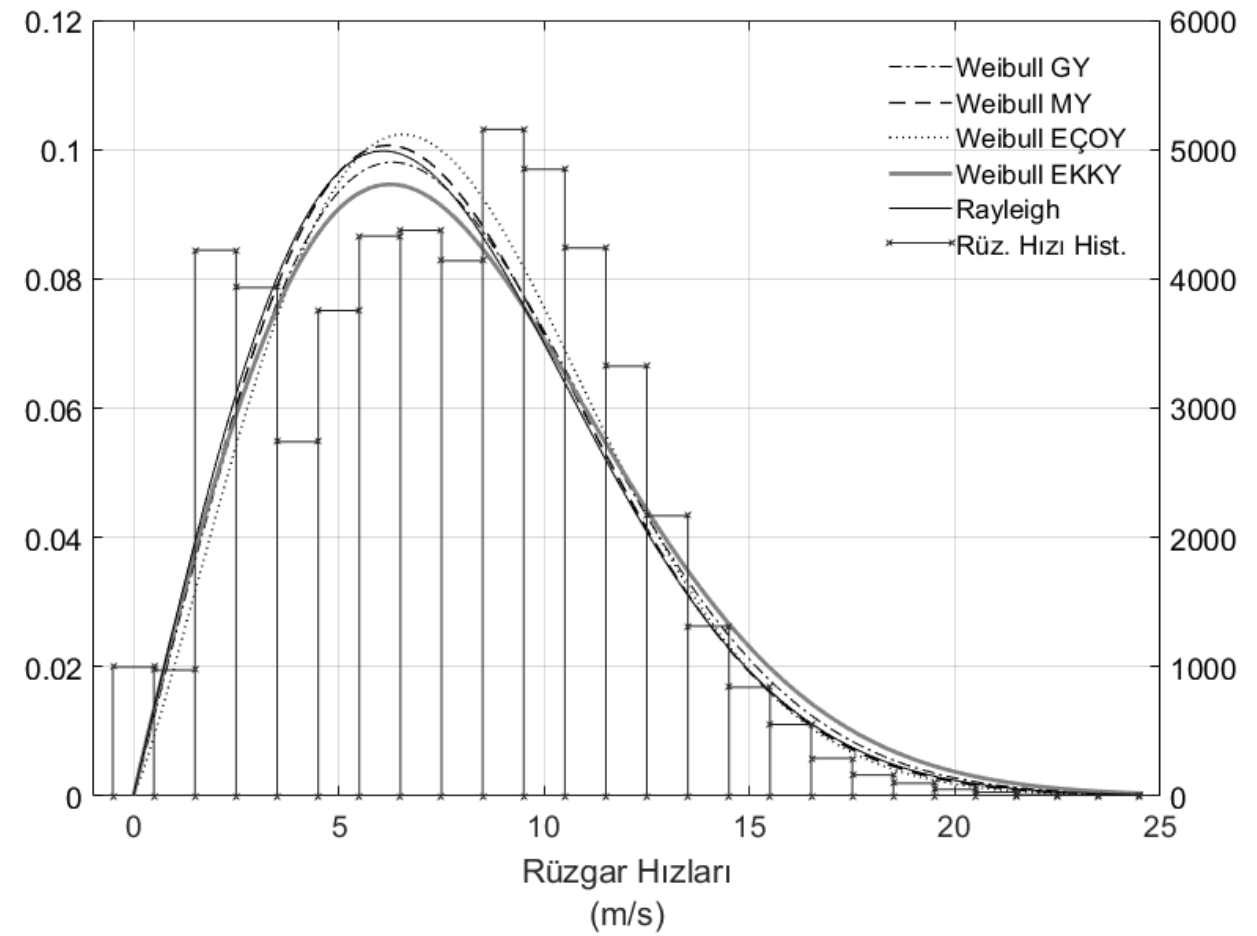

Şekil 5 Weibull olasılık yoğunluk fonksiyonları ve rüzgar hızı verilerinin histogramı

\section{4. İstatistiksel Hata Metrikleri}

Rüzgar verisi analizlerinin gerçekleştirildiği çalışmalarda sıklıkla tercih edilen hata metrikleri üzerinden farklı yöntemler kullanılarak elde edilen Weibull dağılımlarının, veriye uygunlukları irdelenmiştir. Elde edilen sonuçlar Tablo - 2 içerisinde verilmiştir.

Şekil incelendiğinde, elde edilen olasılık yoğunluk fonksiyonları kullanılması durumunda, bazı rüzgar hızlarına ait olasılık yoğunluklarının eksik, bazılarında ise gerçekte olduğundan fazla elde edildiği görülmektedir. Bu durum olasılık yoğunluk fonksiyonlarının eldeki veriye uyumluluğu ile alakalı bir durumdur. İstatistiksel hata analiz yöntemleri yardımıyla söz konusu olasılık yoğunluk fonksiyonları arasından, eldeki veriye en çok uyumluluk gösteren olasılık yoğunluk fonksiyonunun tespiti yapılabilir. Bu amaçla, hata analizlerinde sıklıkla kullanılan testlerden bazıları kullanılarak gerekli görülen inceleme sonucu Tablo - 2 ile verilen sonuçlar elde edilmiştir. 
Tablo 2 Weibull dă̆gllmlarınin istatistiksel hata metrikleri

\begin{tabular}{c|c|c|c|c|c|c}
\hline \multirow{2}{*}{$\begin{array}{c}\text { Matematiksel } \\
\text { Yöntemler }\end{array}$} & $\begin{array}{c}\text { Ort. Hata } \\
\text { (MSE) }\end{array}$ & $\boldsymbol{R}^{\mathbf{2}}$ & $\begin{array}{c}\text { Kök Ort. } \\
\text { Kare Hata } \\
\text { (RMSE) }\end{array}$ & $\begin{array}{c}\text { Ki-Kare Testi } \\
\boldsymbol{\chi}^{\mathbf{2}} \\
\text { (Chi-Square) }\end{array}$ & $\begin{array}{c}\text { Ort. Mutlak } \\
\text { Hata } \\
\text { (MAE) }\end{array}$ & $\begin{array}{c}\text { Ort. Mutlak } \\
\text { Yüzde Hata } \\
\text { (MAPE) }\end{array}$ \\
\hline $1^{-7}$ & & $10^{-3}$ & $10^{-6}$ & $10^{-4}$ & $10^{-3}$ \\
\hline$G Y$ & 0.0099 & 0.9999997 & 0.0315 & 0.0257 & 0.0617 & 0.6171 \\
\hline$E Y$ & 0.0268 & 0.9999993 & 0.0518 & 0.0697 & 0.1015 & 1.0155 \\
\hline$E K O Y$ & 0.0026 & 0.9999999 & 0.0162 & 0.0068 & 0.0318 & 0.3178 \\
\hline Rayleigh & 0.1156 & 0.9999971 & 0.1075 & 0.3005 & 0.2108 & 2.1085 \\
\hline
\end{tabular}

Tablo - 2 incelendiğinde, en çok olabilirlik yöntemi ile elde edilen Weibull dağılımının, diğerlerine kıyasla daha düşük hata değerleri vermiş olduğu gözlemlenebilmektedir. Elde edilen hata değerleri oldukça düşük değerlerde elde edilmiş olsa dahi, Şekil - 5 ile verilen çizim incelendiğinde, olasılık yoğunluk fonksiyonlarının bazı rüzgar hızları için doğru olasılık yoğunluklarını veremediği görülmektedir. Gerçek olasılık yoğunlukları ile olasılık yoğunluk fonksiyonları üzerinden elde edilebilecek değerler arasındaki fark, bu olasılık yoğunluk fonksiyonları ile gerçekleştirilecek çalışmaların doğruluğunu etkileyecektir. Özellikle, enerji potansiyeli çalışmalarında, rüzgar enerjisinden elde edilebilecek elektrik enerjisi miktarının rüzgar hızının küpü ve olasılık yoğunluğu ile doğru orantılı olması nedeniyle, bu farklılıkların sonuç üzerindeki etkileri daha büyük olacaktır.

Basit Weibul dağılımı, en yüksek olasılık yoğunluğuna sahip olan, baskın veri etrafında merkezlenebilen tek tepeli bir dağılımdır. Ancak rüzgâr hız verisinde, özellikle yıllık verilerde, farklı dönemlerde farklı rüzgar hızlarının hâkim olması mümkün olabilir. Bunun neticesinde verilerin olasılık dağılımları, birden fazla tepeye sahip olarak şekillenebilir. Böylesi dağılımların ifadesinde, karma dağılımların kullanımı daha uyumludur.

\section{Karma Weibull Dağılımı}

Karma dağılımlar, birden fazla olasılık yoğunluk fonksiyonunun farklı oranlarda katılımı ile ifade edilen dağılımlardır [17]. Bu çalışmada, Weibull dağılımının rüzgar hızlarının olasılık dağılımlarının ifadesindeki kanıtlanmış başarısı dikkate alınarak, karma Weibull dağılımının kullanılması uygun görülmüştür. Rüzgar enerjisi potansiyeli çalışmalarında, genellikle 0 ile $30 \mathrm{~m} / \mathrm{s}$ arasında arasındaki hızlar dikkate alınmaktadır. Çok geniş bir aralık olmaması ve yapılacak çalışmalarda işlem kalabalığını fazla artırmamak sebebiyle, iki bileşenli karma Weibull dağılımı kullanımı esas alınmıştır.

İki bileşenli Weibull dağılımına ait eşitlikler aşağıda verilmiştir.

$$
\begin{aligned}
& f f\left(v ; w, k_{1}, c_{1}, k_{2}, c_{2}\right)=w f\left(v ; k_{1}, c_{1}\right)+(1-w) f\left(v ; k_{2}, c_{2}\right) \\
& f f\left(v ; w, k_{1}, c_{1}, k_{2}, c_{2}\right)=w\left\{\frac{k_{1}}{c_{1}}\left(\frac{v}{c_{1}}\right)^{k_{1}-1} e^{-\left(\frac{v}{c_{1}}\right)^{k_{1}}}\right\}+(1-w)\left\{\frac{k_{2}}{c_{2}}\left(\frac{v}{c_{2}}\right)^{k_{2}-1} e^{-\left(\frac{v}{c_{2}}\right)^{k_{2}}}\right\}
\end{aligned}
$$

burada, k ve c değişkenleri, basit weibull dağılımında olduğu gibi, sırasıyla şekil ve ölçek değişkenlerini ifade etmektedir. Diğer bir değişken olan w ise oran değişkenine karşllık gelmektedir.

İki değişkenli Weibull dağılımı için uygulanan farklı değişken hesaplama yöntemleri arasından en düşük hata oranı, en çok olabilirlik yöntemi üzerinden elde edilmiştir. Bu nedenle, iki bileşenli karma Weibull dağılımının parametre hesaplamasında en çok olabilirlik yöntemi kullanılmıştır. Mevcut rüzgar verileri ile çalışılan iki bileşenli karma Weibull dağılımına ait değişkenler aşağıdaki Tablo - 3 ile listelenmiştir.

Tablo 3 İki bileşenli karma Weibull dağıllımı değişkenleri

\begin{tabular}{c|c|c|c|c}
\hline $\boldsymbol{w}$ & $\boldsymbol{k}_{\mathbf{1}}$ & $\boldsymbol{c}_{\mathbf{1}}$ & $\boldsymbol{k}_{\mathbf{2}}$ & $\boldsymbol{c}_{\mathbf{2}}$ \\
\hline 0.2118 & 2.1571 & 3.0300 & 3.0966 & 10.0425 \\
\hline
\end{tabular}

Hesaplanan değişkenler ile iki bileşenli karma Weibull dağılımının olasılık yoğunluk fonksiyonu, Şekil - 4 'te çizdirilmiştir. Şekilden anlaşılacağı üzere elde edilen olasılık yoğunluk fonksiyonu ile mevcut verideki rüzgar hızlarının olasılık dağımı çoğunlukla örtüşmektedir. Olasılık yoğunluk fonksiyonu, verilerin dağılımı ile uyumlu, iki tepeli bir dağılım olarak biçimlenmiş̧ir. 


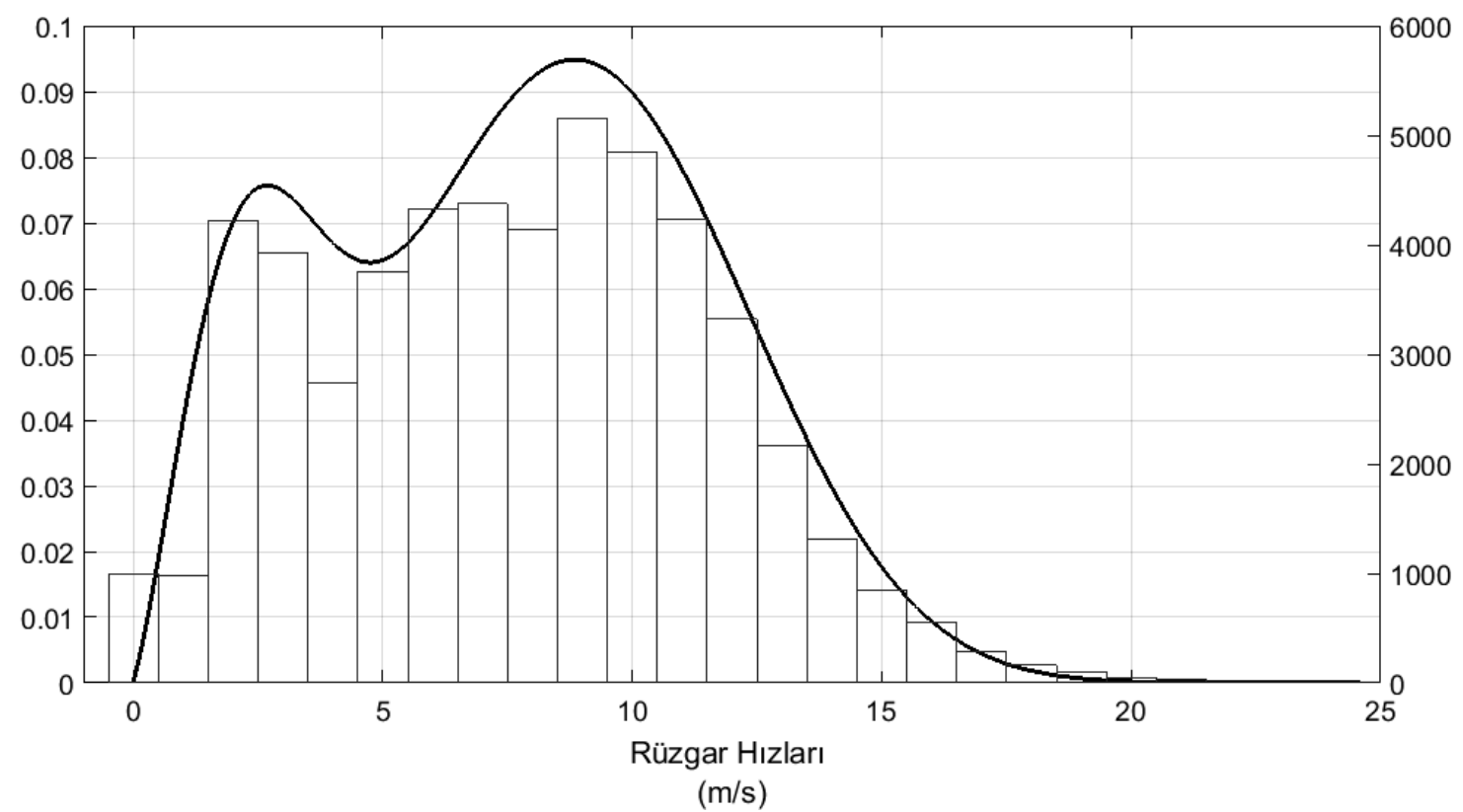

Şekil 6 İki bileşenli Weibull dağıllımı

İki bileşenli karma Weibull dağılımı için gerçekleştirilen hata analizlerinin sonuçları Tablo - 4 ile verilmiştir. Elde edilen sonuçlar, iki bileşenli Weibull dağılımı için elde edilen sonuçlara göre çok daha küçüktür. Anlaşılacağı üzere, iki bileşenli karma Weibull dağılımı, mevcut rüzgâr verilerine daha uyumlu bir dağılım fonksiyonudur.

Tablo 4 İki bileşenli Weibull dağıllımı istatistiksel hata metrikleri

\begin{tabular}{c|c|c|c|c|c|c}
\hline & $\begin{array}{c}\text { Ort. Hata } \\
\text { (MSE) }\end{array}$ & $\boldsymbol{R}^{\mathbf{2}}$ & $\begin{array}{c}\text { Kök Ort. Kare } \\
\text { Hata (RMSE) }\end{array}$ & $\begin{array}{c}\text { Ki-Kare Testi } \\
\chi^{\mathbf{2}} \\
(\text { Chi-Square) }\end{array}$ & $\begin{array}{c}\text { Ort. Mutlak } \\
\text { Hata } \\
\text { (MAE) }\end{array}$ & $\begin{array}{c}\text { Ort. Mutlak } \\
\text { Yüzde Hata } \\
\text { (MAPE) }\end{array}$ \\
\hline & $\mathbf{1 0}^{-\mathbf{1 5}}$ & & $\mathbf{1 0}^{-\mathbf{9}}$ & $\mathbf{1 0}^{-\mathbf{1 5}}$ & $\mathbf{1 0}^{-\mathbf{9}}$ & $\mathbf{1 0}^{-\mathbf{6}}$ \\
\hline $\begin{array}{c}\text { İki Bilessenli Karma } \\
\text { Weibull }\end{array}$ & 0.0555 & 0 & 7.4473 & 1.4420 & 1.4605 & 0.1461 \\
\hline
\end{tabular}

\section{Kapasite Faktörü İncelemesi}

Bir konumdaki rüzgar enerjisi potansiyeli ve bu potansiyel üzerinden elde edilebilecek elektrik enerjisi miktarı, RES yatırımlarının ekonomik ve teknik konularda değerlendirilmeleri açısından oldukça önemli ve belirleyici göstergelerdir. Kapasite faktörü, bu iki bilgiyi içeren önemli bir performans değişkenidir. Belirli bir zaman dilimi içerisinde mevcut rüzgar potansiyeli ve teknik altyapı ile üretilebilecek enerjinin, aynı zaman aralığında, söz konusu tesisin sürekli anma gücünde üretim yapması ile elde edilebilecek enerjiye oranı kapasite faktörünü ifade eder $[18,19]$. Kapasite faktörü aşağıda verilen eşitlikler üzerinden hesaplanabilmektedir.

$$
K F=\frac{P_{\text {ort }}}{P_{n}}
$$

burada, $P_{-}$ort esas alınan zaman aralığı içerisinde üretilen saatlik ortalama güç miktarını, $P_{-} n$ ise ilgili türbine ait anma gücünü ifade etmektedir. P_ort ifadesinin olasılık yoğunluk fonksiyonu üzerinden tanımlamak yolu ile eşitlik tekrar düzenlendiğinde;

$$
K F=\frac{1}{P_{n}} \int_{0}^{\infty} P(v) f(v) \cdot d v
$$

eşitliği elde edilir. Burada $\mathrm{f}(\mathrm{v})$ olasılık yoğunluk fonksiyonunu, $\mathrm{P}(\mathrm{v})$ ise türbin çıkışındaki gücü ifade eder. Çalışmada kullanılan ölçümlerin ait olduğu tesisteki rüzgar türbinine ait güç çıkışının rüzgar hızı aralıklarına göre ifadesi aşağıdaki gibidir.

$$
P_{a v} \rightarrow\left\{\begin{array}{c}
v<V_{\text {Cin }} \rightarrow P_{a v}=0 \\
V_{\text {Cin }} \leq v<V_{n} \rightarrow P_{\text {ort }}=P(v) \\
V_{n} \leq v<V_{\text {Cout }} \rightarrow P_{\text {ort }}=P_{n} \\
V_{\text {Cout }} \leq v \rightarrow P_{a v}=0
\end{array}\right.
$$

yukarıda verilen ifadelere göre denklem tekrar düzenlendiğinde, 


$$
\begin{aligned}
& K F=\frac{1}{P_{n}}\left[\int_{V_{\text {Cin }}}^{V_{n}} P(v) f(v) \cdot d v+\int_{V_{n}}^{V_{\text {Cout }}} P_{n} f(v) \cdot d v\right] \\
& K F=\frac{1}{P_{n}} \int_{V_{\text {Cin }}}^{V_{n}} P(v) f(v) \cdot d v+\int_{V_{n}}^{V_{\text {Cout }}} f(v) \cdot d v \\
& K F=\frac{1}{P_{n}} \int_{V_{\text {Cin }}}^{V_{n}} P(v) f(v) \cdot d v+F\left(V_{\text {Cout }}\right)+F\left(V_{n}\right)
\end{aligned}
$$

olarak elde edilir. Burada rüzgar hızına göre değişmekte olan güç ifadesi $\mathrm{P}(\mathrm{v})$ için türbinin güç eğrisi üzerinden polinom uydurma yöntemi ile bir bağıntı elde edilebilir. Ölçümlerin alındığı tesiste kullanılan, 2,5 MW anma gücündeki rüzgar türbinine ait güç eğrisi Şekil - 7 ile verilmiştir. Güç eğrisi üretici tarafindan sunulan veriler üzerinden elde edilmiştir.

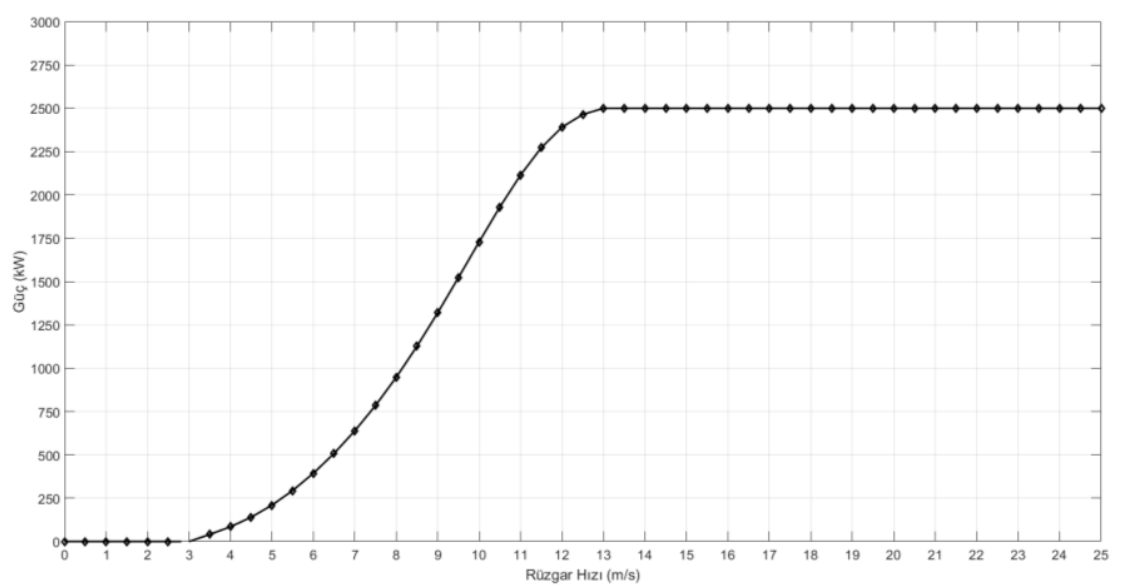

Şekil 7 Ölçümlerin alındı̆̆ sahadaki rüzgar türbinine ait güç eğrisi

İncelenen güç eğrisi üzerinden $V_{-}$Cin ile V_n hızları arasındaki güç eşitliği için güç eğrisi üzerinden, eğri uydurma yöntemleri ile aşağıdaki polinom elde edilmiştir.

$$
P(v)=0.0033 v^{7}-0.1788 v^{6}+3.9268 v^{5}-46.1787 v^{4}+316.0808 v^{3}-1235.2369 v^{2}+2605.8469 v-2325.8387
$$

Elde edilen polinom Eşitlik (22)'de yerine yazıldıktan sonra elde edilen ifade, çalışmada incelenen her bir olasılık yoğunluk fonksiyonu için ayrı ayrı çözdürülmüştür. Ulaşılan değerler Tablo - 5 ile listelenmiştir. Kapasite faktörü değerlerinin doğruluğunun sınanması amacıyla, mevcut verilerdeki üretim miktarları üzerinden sahaya ait gerçek kapasite faktörü değeri hesaplanır ve bu değer ile hesaplanan değerler arasındaki hata, tablonun en sağdaki kolonunda yüzdesel olarak verilmiş̧tir. Sonuçlar incelendiğinde, gerçek kapasite faktörü değerine en çok yaklaşabilen olasılık dağılımı, iki bileşenli karma Weibull dağılımı olduğu görülür. En yüksek hatayı ise Rayleigh dağılımı vermiştir.

\begin{tabular}{ccc}
\hline & Kapasite Faktörü & Hata \\
\hline Enerji Üretimi & 0.4432 & - \\
\hline Weib. $M Y$ & 0.3906 & $\% 11.85$ \\
\hline Weib. GY & 0.4046 & $\% 8.70$ \\
\hline Weib. EÇOY & 0.4037 & $\% 8,90$ \\
\hline Weib. EKKY & 0.4142 & $\% 6.54$ \\
\hline Rayleigh & 0.3877 & $\% 12.51$ \\
\hline Weibull Mixture & 0.4177 & $\% 5.14$ \\
\hline
\end{tabular}

\section{Sonuç}

Rüzgar hızlarının olasılık dağılımlarının ifadesinde Weibull dağılımlarının kullanımı başarısını kanıtlamış bir yaklaşım olarak literatürde sıklıkla başvurulmaktadır. Ancak bazı durumlarda, özellikle geniş zamanlı rüzgar verilerinde, yüksek olasılık dağılımına sahip birden fazla ve birbirinden farklı rüzgar hızlarının gerçekleşebilmesi söz konusudur. Böylesi durumlarda, tek tepeli bir dağılım olan Weibull dağılımının kullanımı, yapılacak hesaplamalarda yeterli doğruluğu elde edebilmek açısında uygun olmayabilir. Bunun yerine, çok tepeli olasılık dağılımlarını ifade edebilen karma olasılık dağılımlarının kullanımı daha uygun olacaktır. Diğer taraftan, iki farklı Weibull dağılımının bir oran değişkeni üzerinden katılımı ile elde edilebilen iki bileşenli Weibull dağılımı, tek tepeli dağılımlara da uygunluk gösterebilmektedir. Bu çalışmada, faaliyette olan bir RES üzerinden alınan rüzgar ve enerji üretim verileri incelenerek, karma dağılımların rüzgar enerji potansiyeli çalışmalarına uygunluğu irdelenmiştir. Bu amaçla, sahadan alınan rüzgar hızı ölçümlerinin, farklı matematiksel yöntemler üzerinden elde edilen değişkenler ile basit Weibull dağılımları oluşturulmuştur. Sonrasında bu dağılımların veriye uygunluklarını ölçmek üzere istatistiksel hata analizleri kullanılmıştır. Yapılan hata analizleri neticesinde Weibull 
değişkenleri hesaplamasına en uygun matematiksel yöntemin, ilgili literatürü destekler nitelikte, en çok olabilirlik yöntemi olduğu sonucuna varılmıştır. Çalışmanın ikinci aşamasında, rüzgar hızlarının olasılık dağılımları, iki bileşenli Weibull dağılımı üzerinden ifade edilmeye çalışılmıştır. Beş değişkene sahip olan bu karma olasılık dağılımının değişkenlerinin hesaplamasında, çalışmanın önceki kısmında en düşük hata değerlerini veren yöntem olan en çok olabilirlik yönteminden faydalanılmıștır. Elde edilen iki bileşenli Weibull dağılımı, ölçümlenen rüzgar hızlarının olasılık dağılımına daha yüksek uyumluluk göstermiş ve gerçekleştirilen hata analizleri neticesinde elde edilen sonuçlar, basit Weibull dağılımı için elde edilen değerlerden çok daha düşük çıkmıştır. Çalışmanın son aşamasında ise, rüzgar enerjisi potansiyeli çalışmalarında oldukça önemli bir yere sahip olan kapasite faktörü değeri incelenmiştir. Çalışmada incelenen tüm olasılık dağılımları için kapasite faktörleri ayrı ayrı hesaplanmıştır. İncelenen veri, faaliyette olan bir RES üzerinden alınan rüzgar hızı ve enerji çıkışı ölçümlerini içeriyor olması münasebetiyle, sahaya ait gerçek kapasite faktörünün elde edilebilmesine imkan sağlamaktadır. Hesaplanan kapasite faktörleri arasından, gerçek kapasite faktörüne en yakın değeri \%5.14 hata ile iki bileşenli Weibull dağılımı vermiştir. Diğer dağılımlar ise, daha yüksek farklar ile kapasite faktörünü hesaplayabilmektedir. Bu durum, iki bileşenli Weibull dağılımlarının, rüzgar enerjisi potansiyeli çalışmalarına gösterdiği uyumluluğu kanıtlar niteliktedir. 


\section{Kaynakça}

[1] "BP Energy Outlook 2018 Edition”, BP, 2018

[2] “World Energy Investment 2018”, IEA, 2018

[3] Şenel, M. C., \& Koç, E. (2015). DÜNYADA VE TÜRKIYE’DE RÜZGÂR ENERJISII DURUMU-GENEL DEĞERLENDIRME. Engineer \& The Machinery Magazine, (663).

[4] Carta, J. A., Ramirez, P., \& Velazquez, S. (2009). A review of wind speed probability distributions used in wind energy analysis: Case studies in the Canary Islands. Renewable and sustainable energy reviews, 13(5), 933-955.

[5] Chadee, J. C., \& Sharma, C. (2001). Wind speed distributions: a new catalogue of defined models. Wind Engineering, 25(6), 319337.

[6] Wais, P. (2017). A review of Weibull functions in wind sector. Renewable and Sustainable Energy Reviews, 70, 1099-1107.

[7] Wang, J., Huang, X., Li, Q., \& Ma, X. (2018). Comparison of seven methods for determining the optimal statistical distribution parameters: A case study of wind energy assessment in the large-scale wind farms of China. Energy, 164, 432-448.

[8] Hui, L. I., \& Fang, Z. H. A. N. G. (2014). Summary on wind speed distribution and its parameter estimation. Advanced Materials Research.

[9] Kestane, Ö., \& Ülgen, K. (2017). Techno-economic analysis of wind power plants: A case study of Milas-Turkey. Energy Sources, Part B: Economics, Planning, and Policy, 12(12), 1088-1100.

[10] Carta, J. A., \& Ramirez, P. (2007). Analysis of two-component mixture Weibull statistics for estimation of wind speed distributions. Renewable energy, 32(3), 518-531.

[11] Şahin, A. D. (2001). Türkiye rüzgarlarının alan-zaman modellemesi (Doctoral dissertation).

[12] Manwell, J. F., McGowan, J. G., \& Rogers, A. L. (2010). Wind energy explained: theory, design and application. John Wiley \& Sons.

[13] Tuller, S. E., \& Brett, A. C. (1984). The characteristics of wind velocity that favor the fitting of a Weibull distribution in wind speed analysis. Journal of Climate and Applied Meteorology, 23(1), 124-134.

[14] International Electrotechnical Commission. (1998). Wind Turbine Generator Systems - Part 12: Wind Turbine Power Performance Testing. IEC Standard, Publication IEC, 61400-12.

[15] Akdağ, S. A., \& Dinler, A. (2009). A new method to estimate Weibull parameters for wind energy applications. Energy conversion and management, 50(7), 1761-1766.

[16] Genc, A., Erisoglu, M., Pekgor, A., Oturanc, G., Hepbasli, A., \& Ulgen, K. (2005). Estimation of wind power potential using Weibull distribution. Energy Sources, 27(9), 809-822.

[17] Açıkgöz, I. (2007). Sonlu karma dagılımlarda parametre tahmini (Doctoral dissertation, PhD Thesis, Graduate School of Natural and Applied Sciences, Ankara University, Turkey).

[18] Çetin, N. S., Çelik, H., \& BaĢaran, K. (2011, May). Rüzgâr türbinlerinde kapasite faktörü ve türbin sınıfı ilişkisi. In 6th International Advanced Technologies Symposium (IATS'11) (pp. 131-136).

[19] Akpinar, E. K., \& Akpinar, S. (2005). An assessment on seasonal analysis of wind energy characteristics and wind turbine characteristics. Energy conversion and management, 46(11-12), 1848-1867. 